\title{
Kronik Hepatit B Virüs Enfeksiyonu Olan Hastalarda Hepatit A Virüs Seroprevalansı
}

\author{
Hepatitis A Virus Seroprevalence in Patients with Chronic Hepatitis B Virus \\ Infection
}

\author{
Sedef Zeliha ÖNER ${ }^{1}$, Emine TÜRKOĞLU²
}

\author{
${ }^{1}$ Turhal Devlet Hastanesi, Tibbi Mikrobiyoloji Laboratuvarı, Tokat, Türkiye \\ ${ }^{2}$ Turhal Devlet Hastanesi, Enfeksiyon Hastalıkları ve Klinik Mikrobiyoloji Kliniği, Tokat, Türkiye
}

Geliş tarihi: 10.01.2020 Kabul tarihi: 08.06.2020 DOI: 10.17517/ksutfd.672913

Özet

Amaç: Bu çalışmada, Kronik Hepatit B tanısı ile takipli hastaların Hepatit A seroprevalansının retrospektif olarak araştırılması ve duyarlı kişilerin aşılanması amaçlanmıştır.

Gereç ve Yöntemler: Kasım 2018-Kasım 2019 tarihleri arasında hastanemiz enfeksiyon hastalıkları polikliniğine başvuran kronik hepatit B tanılı hastaların HAV Ab-IgG sonuçları değerlendirildi. HAVAb-IgG tetkiki, ARCHITECT i2000SR analizatöründe ARCHITECT ${ }^{\circledast}$ HAVAb-IgG test kiti ile Kemilüminesan Mikropartikül İmmünoassay(CMIA) yöntemi kullanılarak araştırılmıştır. Verilerin istatistiksel analiz Statistical Package for Social Scienses (SPSS) 21 (Inc. Chicago, Illinois, ABD) istatistik paket programıla analiz edilmiştir.

Bulgular: Kronik hepatit B tanısıyla izlenen 138 hasta değerlendirildi. Hastaların 27’sinde HAV Ab-IgG tetkiki yapılmamıştı. Çalışmaya 111 hasta dahil edildi. Hastaların 64’ü (\%57,7) kadın, 47’si (\%42,3) erkekti. Hastalar 15-84 yaş aralığına sahipti.

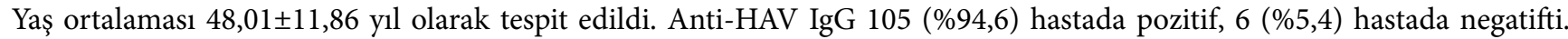
Anti-HAV IgG pozitif hastaların yaş ortalaması 49,25 $\pm 11,31$ tespit edildi. Anti-HAV IgG negatif olan hastaların 2'si (\%33,3)

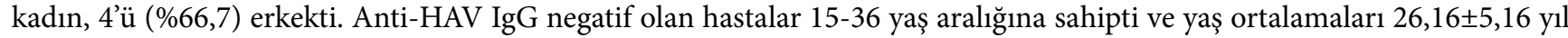
olarak tespit edildi.

Sonuç: Kronik hepatit B virüs enfeksiyonu olan hastalarda hepatit A virüs seroprevalansı $\% 94,6$ olarak bulundu. HBV enfeksiyonu olan hastalarda HAV Ab-IgG tetkiki yapılmalı ve Anti-HAV IgG negatif olan hastalar aşılama programına alınmalıdır.

Anahtar kelimeler: Bağışıklama, Hepatit A, Kronik hepatit B, Seroprevalans

\section{Abstract}

Objective: The aim of this study was to retrospectively investigate Hepatitis A seroprevalence in patients with chronic hepatitis $\mathrm{B}$ and to vaccinate susceptible individuals.

Material and Methods: Between November 2018 and November 2019, HAV Ab-IgG results of patients with chronic hepatitis $\mathrm{B}$ admitted to hospital infectious diseases outpatient clinic were evaluated. The HAVAb-IgG assay was investigated on the ARCHITECT i2000SR analyzer with the ARCHITECT ${ }^{\circledast}$ HAVAb-IgG assayusing the Chemiluminescent Microparticle Immunoassay (CMIA) method. Statistical analysis of the data was analyzed using the Statistical Packagefor Social Sciences 21 statistical package program.

Results: 138 patients with chronic hepatitis B were evaluated. HAV Ab-IgG was not performed in 27 patients. 111 patients were included in the study. 64 (57.7\%) of the patients were female and $47(42.3 \%)$ were male. The patients were between the ages of $15-84$. The mean age was $48.01 \pm 11.86$ years. Anti-HAV IgG was positive in $105(94.6 \%)$ patients and negative in $6(5.4 \%)$ patients. The mean age of anti-HAV IgG positive patients was $49.25 \pm 11.31$ years. Of the patients with anti-HAV IgG negative, 2 (33.3\%) were female and 4 (66.7\%) were male. The patients were between 15-36 years old. The mean age was $26.16 \pm 5.16$ years.

Conclusion: Seroprevalence of hepatitis A virus was $94.6 \%$ in patients with chronic hepatitis B virus infection. HAV AbIgG should be tested in patients with HBV infection and patients who are anti-HAV IgG negative should be included in the vaccination program.

Keywords: Immunization, Hepatitis A, Chronic hepatitis B, Seroprevalence

Yazışma Adresi: Sedef Zeliha ÖNER Turhal Devlet Hastanesi Tibbi Mikrobiyoloji Laboratuvarı, Tokat, Türkiye, Telefon: 05054880526

e-mail: tezelsedef@hotmail.com ORCID No (S1rasıly): 0000-0002-9964-2526, 0000-0003-4418-4692 


\section{GİRIŞ}

Ülkemizde viral hepatitler karaciğer sağlığını tehdit eden en önemli risk faktörlerindendir. Hepatit B Virus (HBV) enfeksiyonunu çocukluk çağında \%90 sıklıkta asemptomatik ve yetişkinlerde \%20-30 sıklıkta semptomatik seyreder. HBV perinatal dönemde bulaşırsa $\% 90$, beş yaşına kadar bulaşırsa \%20-30 ve erişkinlerde bulaşırsa \%2-5 civarında kronikleşir. HBV'ye karşı en etkili korunma yöntemi aşılamadır. Ülkemizde aşılama hızı 2016 itibariyle \%98'e yükselmiş ve 5 yaş altı hepatit B hastalığı insidansı \%1’in altına düşmüştür. Ülkemizde aşılama ile yeni gelişen kronik HBV enfeksiyonları önemli ölçüde azalmıştır (1).

Hepatit A virüsü (HAV), HAV bulaşmış yiyecek ve su alımı veya enfekte kişiyle doğrudan temas yoluyla bulaşır. Hepatit A kronik karaciğer hastalığına neden olmaz ve nadiren ölümcüldür. Hepatit A fulminan hepatit (akut karaciğer yetmezliği) kliniği ile seyrederse genellikle ölümcüldür. Dünya Sağlık Örgütü, 2016 yılında viral hepatit nedeniyle ölümlerin \%0,5’ine hepatit A’nın neden olduğunu bildirmiştir. Güvenli su temini, gıda güvenliği, iyileștirilmiş hijyen koşulları ve hepatit A aşısı hastalıktan korunmak için en etkili yoldur(2).

HAV enfeksiyonu, kronik hepatit B hastalarında sağlıklı kişilerde görülenden daha ağır bir klinik seyir ve daha yüksek bir ölüm oranına sahiptir. Ağır klinik seyir ve yüksek ölüm oranındaki farklılıklar, yaşı hastalarda, kronik hepatit B veya sirozun histolojik bulgusu olanlarda asemptomatik hepatit B taşıyıcılarından daha belirgindir (3).

Bu çalışmada, Kronik Hepatit B tanısı ile takipli hastaların Hepatit A seroprevalansının retrospektif olarak araştırılması ve duyarlı kişilerin aşılanması amaçlanmıştır.

\section{GERECุ VE YÖNTEMLER}

Kasım 2018-Kasım 2019 tarihleri arasında hastanemiz enfeksiyon hastalıkları polikliniğine başvuran kronik hepatit B tanılı hastaların yaşı, cinsiyeti, HAV Ab-IgG sonuçları hastane bilgi yönetim sistemi ile retrospektif olarak değerlendirildi. HAVAb-IgG tetkiki, çalışmanın yapıldı̆̆ı tarihler arasında hastaneye başvuru sırasında yapılmıştır. HAVAb-IgG tetkiki, ARCHITECT i2000SR (AbbottDiagnostics, Mannheim,

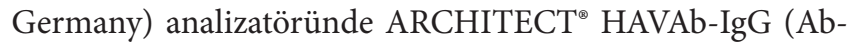
bott, Wiesbaden, Almanya) test kiti ile CMIA yöntemi kullanılarak araştırılmıştır. Tüm sonuçlar signalsample/cutoff (S/CO) olarak ifade edildi. Eşik değeri <1,0 olan numuneler non-reaktif olarak değerlendirildi. Eşik değeri $>1,0$ olan örnekler reaktif olarak kabul edildi.

\section{İstatistiksel analiz}

Verilerin istatistiksel analiz Statistical PackageforSocialScienses (SPSS) 21 (Inc. Chicago, Illinois, ABD) istatistik paket programıyla analiz edilmiştir. Sürekli değişkenler ortalama \pm standart sapma, minimum ve maksimum değerler ve kategorik değişkenler sayı ve yüzde olarak ifade edilmiştir. Çalışmada Anti-HAV IgG pozitiflik oranı ulusal literatürdeki oranlarla binom testi kullanılarak karşılaştırılmıştır.

\section{BULGULAR}

Kronik hepatit B tanısıyla izlenen 138 hasta değerlendirildi. Hastaların 27'sinde HAV Ab-IgG tetkiki yapılmamıştı. Çalışmaya 111 hasta dahil edildi. Hastaların 64'ü $(\% 57,7)$ kadın, 47’si $(\% 42,3)$ erkekti. Hastalar 15-84 yaş aralığına sahipti. Yaş ortalaması 48,01 $\pm 11,86$ yll olarak tespit edildi. Anti-HAV IgG $105(\% 94,6)$ hastada pozitif, $6(\% 5,4)$ hastada negatifti. Anti-HAV IgG pozitif hastaların yaş ortalaması $49,25 \pm 11,31$ tespit edildi. Anti-HAV IgG negatif olan hastaların 2'si $(\% 33,3)$ kadın, 4’ü $(\% 66,7)$ erkekti. Anti-HAV IgG negatif olan hastalar 15-36 yaş aralığına sahipti ve yaş ortalamaları $26,16 \pm 5,16$ yil olarak tespit edildi.

\section{TARTIŞMA}

HAV endemisitesinin sinıflandirılması seroprevalans oranlarına göre yapılmaktadır. Yüksek endemisite (10 yaşına kadar \%90 seropozitiflik), orta endemisite (10 yaşına kadar < \%50 seropozitiflik ile 15 yıl içinde \%90 seropozitiflik), düşük endemisite (15 yaşına kadar < \%50 seropozitiflik ile 30 yaşında \%50 seropozitiflik) ve çok düşük endemisite (30 yaşına kadar < \%50 seropozitiflik) olarak sınıflandırılmıştır (4). Ülkemiz 1990’ li yıllarda yüksek endemisiteye sahipken 2000' li yıllardan sonra orta endemisitede yer almıştır (5).

Ülkemizde HAV hala endemik olarak ortamda bulunmakla birlikte görülme sıklığı giderek azalmakta, virüsle karşılaşma yaşı, adolesan ve genç erişkin döneme doğru kaymaktadır (1). Bu çalışmada, Anti-HAV IgG 105 (\%94,6) hastada pozitif bulundu. Anti-HAV IgG pozitif hastaların yaş ortalaması 49,25 ve negatif olan hastaların yaş ortalaması ise 26,16 yil olarak tespit edildi. 2012-2013 yılları arasında rastgele seçilen 167 sağlık çalışanıyla yapılan bir çalışma da Anti-HAV IgG \%43,1 pozitif bulunurken pozitif sonuç alanların yaş ortalaması 33.4, olumsuz sonuçların ise 27,4 yıl olduğu görülmüştür (6).İstanbul ilinde 2011-2013 yılları arasında erişkin yaş gruplarıyla yapılan bir çalışmada Anti-HAV IgG $\% 80$ pozitif bulunurken 17-27 yaş grubunda seropozitiflik \%42,8 olarak bulunmuştur (7).Manisa ilinde yapılan bir çalışmada ise hepatit A seronegatifliği \%24,4 olarak saptanmıştır. Hepatit A seronegatifliğinin en yüksek olduğu yaş grupları 2-9, 10-19 ve 20-29 olup sirasiyla, $\% 78,5, \% 65,8$ ve $\% 31,3$ olarak bulunmuştur. 30 yaş ve üzeri gruplarda seronegatiflik \%0,0-\%5,5 olarak değişmekteydi (8). Bu çalışmada Anti-HAV IgG seropozitifliği yüksek oranda tespit edilmiştir. Bunun hastaların yaş ortalamasının yüksek olmasından kaynaklandığını düşünmekteyiz. Negatif olan hastaların yaş ortalaması literatürle uyumlu idi.

$\mathrm{Bu}$ çalışmada seronegatif hastaların yaş ortalamaları yüksek bulunmuştur. Ayrıca çalışma için seçilen grubun kronik karaciğer hastalığı olması ayrı bir risk faktörüdür. Sosyoekonomik ve hijyenik koşullardaki iyileşmeler, enfeksiyondaki ortalama yaşta bir artışa, bu da hepatit A nedeniyle morbidite ve mortalitede paradoksal bir artışa neden olmuştur. Semptomatik hepatit, şiddetli hastalık ve ölüm enfeksiyonun daha büyük yaşlarda görülmesi durumunda daha olasıdır (5). 
Akut viral hepatit olgularının değerlendirildiği bir çalışmada HBV ile enfekte hastaların \%2,9'unda HAV ile koinfeksiyon görülmüştür. Bu hastalarda Hepatit A infeksiyonuatipik seyir göstermiştir. Hastalardan birinin kliniği fulminan hepatitle seyretmiştir ve hasta karaciğer yetmezliğinden kaybedilmiştir (9). İzole HAV enfeksiyonu olan hastalar ile HBsAg taşıyıcılarının ve HBV veya HCVıye bağlı kronik karaciğer hastalığı olan hastaların progresyonunun karşılaştırıldığ başka bir çalışmada izole HAV enfeksiyonu olan hiçbir hastada komplikasyon gelişmediği görülmüştür. Fulminan veya submassif hepatit, HBsAg taşıyıcılarının \%55 inde ve HBV veya $\mathrm{HCV}$ >ye bağlı kronik karaciğer hastalığı olan hastaların \%33>ünde ortaya çıkmıştır. HBsAg taşıyıcılarındaki ölüm oranı \%25, kronik karaciğer hastalığı olan hastalarda \%33 olarak bulunmuştur. Bireylerin yaklaşık \%50〉si 21 ile 30 yaşları arasında HAV enfeksiyonu geçirmiştir. HAV enfeksiyonunun altta yatan kronik karaciğer hastalığı varlığında, özellikle yaşlı bireylerde daha ciddi bir klinik seyre sahip olabileceği görülmüştür (10).

Ülkemizde kronik HBV enfeksiyonu olan hastalarda HAV seroprevalansının değerlendirildiği az sayıda çalışma bulunmaktadır (11-13). Kronik HBV enfeksiyonu olan yaşları 18 ile 30 arasında değişen 239 erkek hastanın dahil edildiği çalışmada \%74,9'unda anti- HAV IgG seropozitifliği bulunmuştur (11). Afyon ilinde 95 kronik hepatit B hastası ve 178 inaktif hepatit $\mathrm{B}$ yüzey antijeni (HbsAg) taşıyıcılığı olan hastanın dahil edildiği bir çalışmada. Anti-HAV IgG \%94,2 pozitif bulunmuştur (12). Kronik hepatit B tanısı olan 100 hastanın dahil edildiği başka bir çalışmada ise Anti-HAV IgG seropozitifliği \%77 olarak bulunmuştur (13). Kronik hepatit B hastası 111 kişinin dahil edildiği bu çalışmada, Anti-HAV IgG seropozitifliği \%94,6 olarak tespit edildi. Çalışmamızın Anti-HAV IgG pozitiflik oranı, seropozitifliğin \%74,9 ve \%77 olarak tespit edildiği ulusal çalışmalardan anlamlı oranda yüksektir ( $\mathrm{p}=0,0001$ ve $\mathrm{p}=0,001$ ). Seropozitifliğin \%94,2 olarak tespit edildiği çalışma ile çalışmamız seropozitiflik oranları arasında ise anlamlı bir farklılık bulunmamıştır $(\mathrm{p}=0,522)$.

Aşılama HBV'ye karşı en etkili korunma yöntemidir. Ülkemizde aşı kapsayıcılığı son yıllarda giderek artmış ve 1999'da \%64 olan aşılama hızları 2016 itibariyle \%98'e yükselmiştir. Bu durum yeni gelişen kronik HBV enfeksiyonlarını önemli ölçüde azalmıştır. 5 yaş altı hepatit B hastalığı insidansı yüzbinde 1'in altına düşmüştür. Hepatit A enfeksiyonundan korunma yöntemleri ise hijyenik yaşam koşullarının sağlanması ve aşılamadır. Ülkemizde 2012 sonunda başlayan hepatit A aşı uygulaması, 1 Mart 2011 ve sonrasında doğan çocuklara 18. ve 24. ayda olmak üzere 2 doz olarak uygulanmaktadır. Ayrıca Hepatit A aşısı risk grubunda yer alan kronik HBV enfeksiyonu olan hastalara, serolojik değerlendirme yapılarak en az 6 ay ara ile 2 doz olarak uygulanmaktadır (1). Retrospektif olarak yapılan bu çalışmada hastaların 27'sinde HAV Ab-IgG tetkiki yapılmadığı görüldü. Hastalar aranarak HAV Ab-IgG tetkiki yapılması amaçlı çağrıldı. Anti-HAV IgG negatif olan 6 hasta bulunmaktaydı. Bu hastalar aşılama programına alındı.
Sonuç olarak, kronik hepatit B virüs enfeksiyonu olan hastalarda hepatit A virüs seroprevalansı \%94,6 olarak bulundu. HBV enfeksiyonu olan hastalarda HAV Ab-IgG tetkiki yapılmalı ve Anti-HAV IgG negatif olan hastalar aşılama programına alınmalıdır.

Çıkar çatışması ve finansman beyanı: Bu çalışmada çıkar çatışması yoktur ve finansman desteği alınmamıştır.

\section{KAYNAKLAR}

1. https://hsgm.saglik.gov.tr/depo/birimler/Bulasici-hastaliklar db/duyurular/Turkiye_Viral_Hepatit_Onleme_ve_Kontrol_ Programi/Turkiye_Viral_Hepatit_Onleme_ve_Kontrol_Programi_TR.pdf Son Erişim Tarihi:19.12.2019.

2. https://www.who.int/en/news-room/fact-sheets/detail/hepatitis-a Son Erişim Tarihi:19.12.2019.

3. Reiss G, Keeffe EB. Review article: hepatitis vaccination in patients with chronic liver disease. Aliment Pharmacol Ther. 2004;19(7):715-27.

4. WHO position paper on hepatitis A vaccines - June 2012. Wkly Epidemiol Rec. 2012;87(28/29):261-76.

5. Aggarwal R, Goel A. Hepatitis A: epidemiology in resource-poor countries. Curr Opin Infect Dis. 2015;285(5):488-96.

6. Tekin A, Sahin AM, Basmaci C, Kes NU, Sönmez E. Hepatitis A seropositivity and characteristics among health care workers in a training and research hospital in Istanbul. Med Sci Discovery. 2016;3(8):296-300.

7. Iraz M, Gültepe B, Doymaz MZ. Erişkin Yaş Gruplarında Hepatit A Seroprevalans1. Abant Med J. 2015;4(1):54-8.

8. Görgel-Kahraman H, Alpay-Özbek Ö, Emek M, Atasoylu G, Sekreter Ö, Ünal B. Manisa ili hepatit A seronegatifliği ve sosyal belirleyicilerle ilişkisi, 2014. Turk Hij Den Biyol Derg. 2019;76(2):131-40.

9. Tekin Koruk S, Gürsoy B, Koruk İ, Yildız Zeyrek F, Unutmaz G, Karaağaç L. ve ark. Akut Viral Hepatit Olgularının Değerlendirilmesi. ViralHepat J. 2006;11(3):132-7.

10. Pramoolsinsap C, Poovorawan Y, Hirsch P, Busagorn N, Attamasirikul K. Acute, hepatitis-A super-infection in HBV carriers, or chronic liver disease related to HBV or HCV. Ann Trop Med Parasitol. 1999;93(7):745-51.

11. Afyon M, Şimşek B. Kronik hepatit B virüs enfeksiyonu olan 1830 yaş arası erkek hastalarda hepatit A seroprevalansı. Gülhane Tip Derg. 2016;58(4):373-6.

12. Türkoğlu E, Demirtürk N. Hepatit B Virusu ile İnfekte Hastalarda Hepatit A Serolojisinin Araştırılması. Med J Bakırkoy. 2015;11(3):116-9.

13. Alpay Y. Kronik Hepatit B Virüsü Enfeksiyonu Olan Hastalarda Hepatit A Virüsü Enfeksiyonunun Seroprevalansının Değerlendirilmesi. Klimik Dergisi. 2019;32(1):19-21. 